Article

\title{
Liquid-Phase Catalytic Oxidation of Limonene to Carvone over ZIF-67(Co)
}

\author{
Yizhou Li, Yepeng Yang, Daomei Chen, Zhifang Luo, Wei Wang, Yali Ao, Lin Zhang, \\ Zhiying Yan * and Jiaqiang Wang *iD
}

National Center for International Research on Photoelectric and Energy Materials, Yunnan Provincial Collaborative Innovation Center of Green Chemistry for Lignite Energy, Yunnan Province Engineering Research Center of Photocatalytic Treatment of Industrial Wastewater, The Universities' Center for Photocatalytic Treatment of Pollutants in Yunnan Province, School of Chemical Sciences \& Technology, Yunnan University, Kunming 650091, China; zh111111ou@163.com (Y.L.); mondaysunday1234@163.com (Y.Y.); dmchen@ynu.edu.cn (D.C.); zhifangluo@126.com (Z.L.); wangwei2@ynu.edu.cn (W.W.); yl_a2019@163.com (Y.A.); echolanchen@163.com (L.Z.)

* Correspondence: zhyyan@ynu.edu.cn (Z.Y.); jqwang@ynu.edu.cn (J.W.); Tel.: +86-871-6503-1567 (Z.Y.); +86-871-6503-1567 (J.W.)

Received: 15 March 2019; Accepted: 16 April 2019; Published: 21 April 2019

check for updates

\begin{abstract}
Liquid-phase catalytic oxidation of limonene was carried out under mild conditions, and carvone was produced in the presence of ZIF-67(Co), cobalt based zeolitic imidazolate framework, as catalyst, using t-butyl hydroperoxide (t-BHP) as oxidant and benzene as solvent. As a heterogeneous catalyst, the zeolitic imidazolate framework ZIF-67(Co) exhibited reasonable substrate-product selectivity (55.4\%) and conversion (29.8\%). Finally, the X-ray diffraction patterns of the catalyst before and after proved that ZIF-67(Co) acted as a heterogeneous catalyst, and can be reused without losing its activity to a great extent.
\end{abstract}

Keywords: liquid-phase catalytic oxidation; limonene; carvone; zeolitic imidazolate frameworks

\section{Introduction}

As we know, the reaction about the allylic oxidation plays a critical role in developing fine chemicals with high additional value from biomass, and has great value in the synthesis of unsaturated aldehydes and ketones [1,2]. Carvone is a main ingredient, derived from plant essential oils, used for cosmetics and food flavors, and is also used in the preservation of meat, fruits, and vegetables because it has good antioxidant activity, analgesic effects, and antibacterial effects [3,4]. In addition, carvone is an important intermediate in industrial chemistry, where it can further be used to synthesize carvone thioether and cyanoacetone [5]. The applicability of traditional methods of transforming limonene to carvone through catalytic oxidation, such as epoxidation and nitrosochlorination, is limited; largely because environmentally unfriendly reagents are often used and poisonous secondary products are produced [6]. Compared with these methods, the use of heterogeneous catalysts has broader applicability prospects in the allylic oxidation of cycloolefins, due to their remarkable advantages in catalyst recovery and stability.

However, current research results show that the selectivity of the catalytic oxidation of limonene to carvone by heterogeneous reaction has not been satisfactory. For instance, 36\% substrate conversion and $25 \%$ selectivity for carvone were obtained by using chromium-containing mesoporous molecular sieves MCM-41 [7]. Lower than 5\% selectivity for carvone was obtained by using the $\left[\mathrm{Fe}^{\mathrm{III}}(\mathrm{BPMP}) \mathrm{Cl}(\mu-\mathrm{O}) \mathrm{Fe}^{\mathrm{III}} \mathrm{Cl}_{3}\right.$ ] complex as catalyst [8]. A $21 \%$ conversion and $20 \%$ selectivity for carvone were obtained in a reaction using Fe/EuroPh catalysts [9]. In another study, high conversion up to $93 \%$ 
of limonene was attained, while the selectivity for carvone was less than 7\% [10]. In our previous study, cobalt-doped mesoporous silica templated by reed leaves exhibited high substrate conversion $(100 \%)$ and relatively good product (carvone) selectivity $(40.2 \%)$ for the allylic oxidation of limonene to carvone [11].

Metal-organic frameworks (MOFs) have attracted considerable attention in catalysis and adsorption in recent years, owing to their advantages, such as high surface areas, well-defined structures, special metal centers, their ease of processing, and their structural diversity [12-16]. Thus, the performance of MOF materials in this reaction has also been reported $[17,18]$, but their application is limited by their thermal and chemical stability [19]. However we are sure that it is valuable to use some MOFs materials in this reaction, and this research has aroused our great interest.

Zeolitic imidazolate frameworks (ZIFs), which are constructed from tetrahedrally coordinated divalent cations $\left(\mathrm{Zn}^{2+}\right.$ or $\left.\mathrm{Co}^{2+}\right)$ linked by the uninegative imidazolate ligands, are a new class of porous metal-organic framework (MOF) [20]. They are widely used in organic synthesis [21-25], $\mathrm{CO}_{2}$ capture of [26], and olefin/paraffin separation [27] because of their excellent thermal and chemical stability. They benefit from strong interactions between imidazolium salts and metal ions, which make the frameworks of zeolitic imidazolates maintain their structural integrity even in water, and this is difficult for other MOFs [28]. Additionally, ZIF-67 has a high-porosity zeolite structure, which is conducive to catalytic reactions. According to our surveys, ZIFs have been widely used to catalyze different types of organic synthesis reactions in recent years, such as cyclohexene hydrogenation [29], glycerol esterification [30], and transesterification reactions [31].To this end, the zeolitic imidazole framework ZIF-67(Co) was selected because ZIF-67 is easy to prepare at large scale in water under ambient conditions without using toxic solvents, and the preparation of ZIF-67(Co) has good reproducibility.

In this continuation of our work, we successfully synthesized ZIF-67(Co) by hydrothermal synthesis, and it displayed good catalytic properties in the catalytic oxidation of limonene. Furthermore, the application of tert-butyl hydroperoxide (t-BHP) to the allylic oxidation of cycloolefins offers an alternative to traditional unfriendly oxidants. In this work, the effects of solvents, oxidants, and reaction temperature on the productivity and reaction time were investigated. Under the optimal conditions, although the conversion of limonene was only $29.8 \%$, we increased the selectivity for carvone to $55.4 \%$, which is more than that in all the literature we have been able to refer to. For comparison, the catalytic activities of more MOFs were also investigated. This is the first report about the oxidation of limonene to carvone over ZIF-67(Co).

\section{Results and Discussion}

\subsection{Characterization of ZIF-67(Co)}

Powder XRD patterns of the ZIF-67(Co) are shown in Figure 1. The diffraction peaks of the $2 \theta$ values at $7.48^{\circ}, 10.42^{\circ}, 12.74^{\circ}$, and $18.06^{\circ}$, were assigned to the (011), (002), (112), and (222) planes of ZIF-67, which has been reported by other researchers [20,21,29]. Figure 1 also reflects the fact that synthetic ZIF-67(Co) is a phase-pure product. Besides, in order to compare the different catalysts' ability about catalyzed the limonene to carvone, some other MOFs have been synthesized successfully and their XRD patterns have been revealed in supplementary material (Figures S1-S5)

The $\mathrm{N}_{2}$ sorption experiments for the ZIF-67(Co) yielded the typical type I isotherms in Figure 2. The Brunauer-Emmett-Teller $\left(\mathrm{S}_{\mathrm{BET}}\right)$ and Langmuir surface areas of ZIF-67 were 1378 and $1805 \mathrm{~m}^{2} / \mathrm{g}$, and the pore volume was $0.62 \mathrm{~cm}^{3} / \mathrm{g}$, which are near to the previously reported values [32,33]. At lower relative pressures, the micropore in the material makes the adsorption capacity increase rapidly, while at higher relative pressures, due to the existence of spin/large porosity nanoparticles structure, the enhancement of adsorption capacity is lower. The pore size distribution curve was calculated by the Horvath-Kawazoe (HK) method, which clearly showed that there were two kinds of micropores in ZIF-67(Co). This result is similar to an earlier work [22]. 


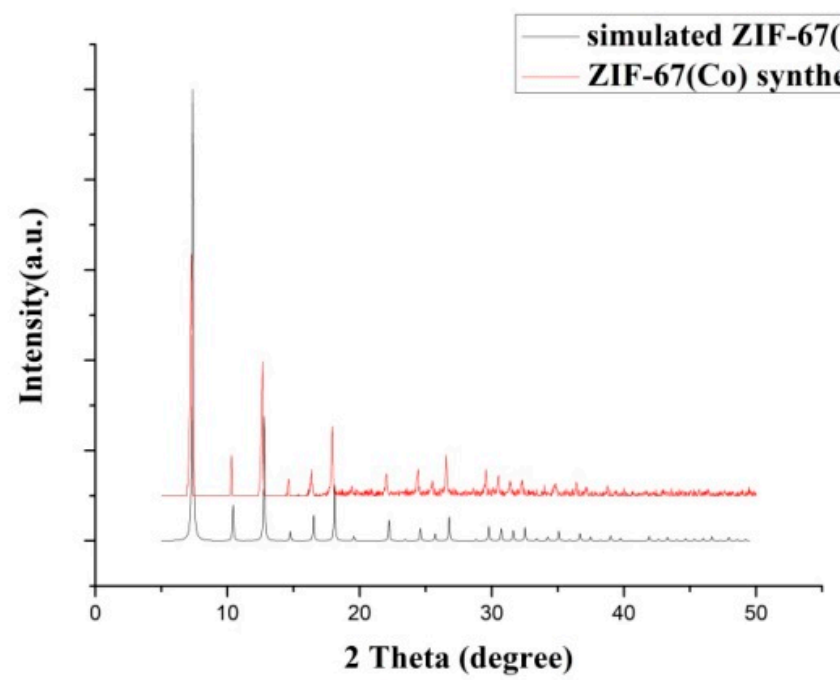

Figure 1. XRD patterns of the zeolitic imidazolate framework ZIF-67(Co).

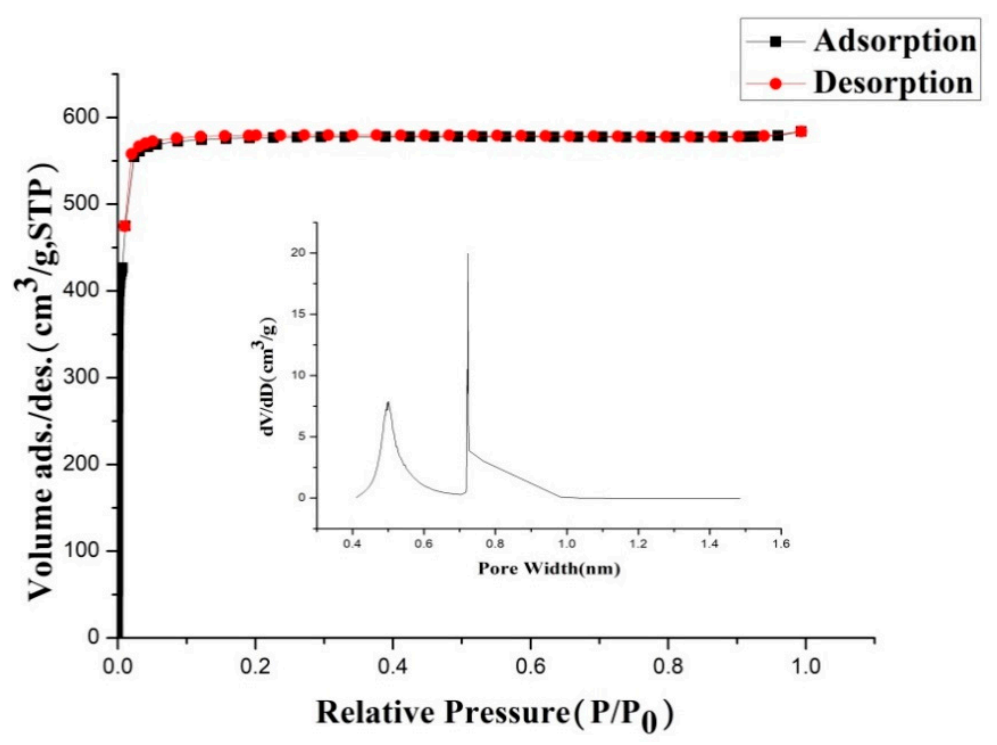

Figure 2. $\mathrm{N}_{2}$ adsorption/desorption isotherms of ZIF-67(Co) samples at $77 \mathrm{~K}$ and Horvath-Kawazoe (HK) pore size distribution curve.

The morphology and particle size of the samples revealed by scanning electron microscopy (SEM) are shown in Figure 3. The SEM picture reveals that the particles were submicroscopic crystals with polyhedral shapes, each surface was a homogeneous quadrilateral, and the particle sizes ranged from 200 to $500 \mathrm{~nm}$. This also proves that the as-synthesized ZIF-67(Co) was composed of submicroscopic crystals.

FT-IR and TGA were employed to obtain further structural information about the ZIF-67(Co). Figure 4 presents FT-IR spectra of ZIF-67(Co) between 400 and $4000 \mathrm{~cm}^{-1}$. The peak at $3420 \mathrm{~cm}^{-1}$ is a contribution of the asymmetric characteristic absorption peaks of $\mathrm{O}-\mathrm{H}$ bonds in hydroxyl groups adsorbed on the surface of materials. There were also some peaks between 500 and $1500 \mathrm{~cm}^{-1}$ caused by plane-bending vibrations and stretching vibrations of the imidazole ring. Meanwhile, the two small peaks at 758 and $534 \mathrm{~cm}^{-1}$ were attributed to the stretching vibration peak of the Co-N bond. In addition, there were two bands at 3134 and $2931 \mathrm{~cm}^{-1}$ caused by the asymmetric absorption vibrations of the $\mathrm{C}-\mathrm{H}$ bond in the methyl groups. 


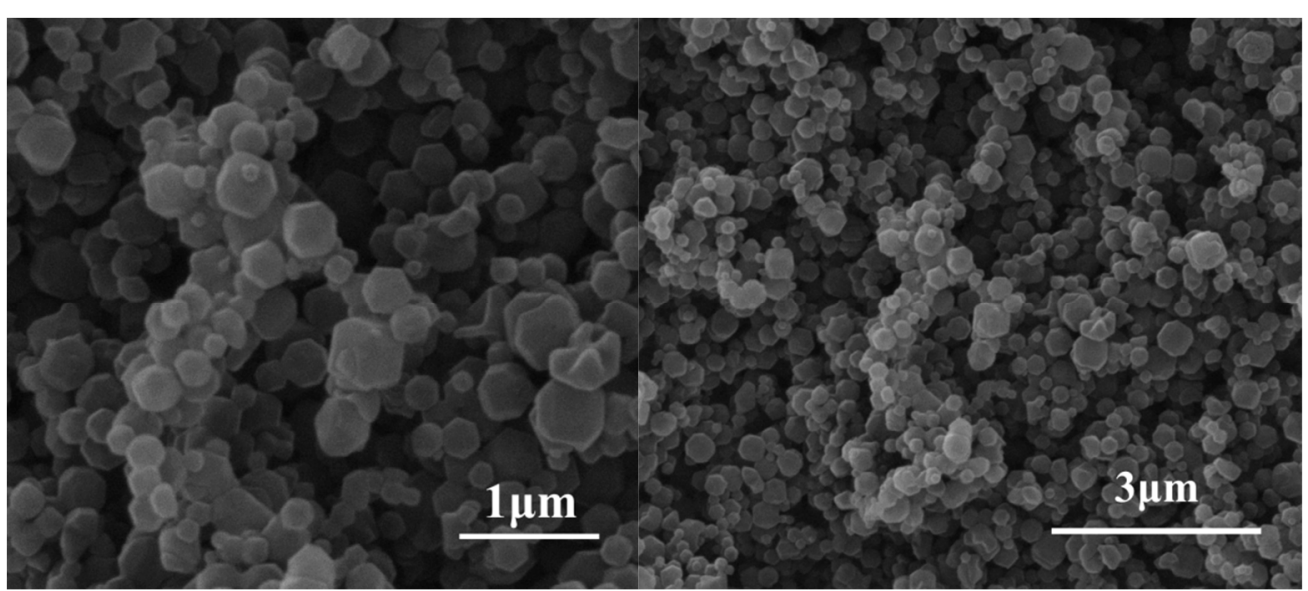

Figure 3. SEM pictures of ZIF-67(Co).

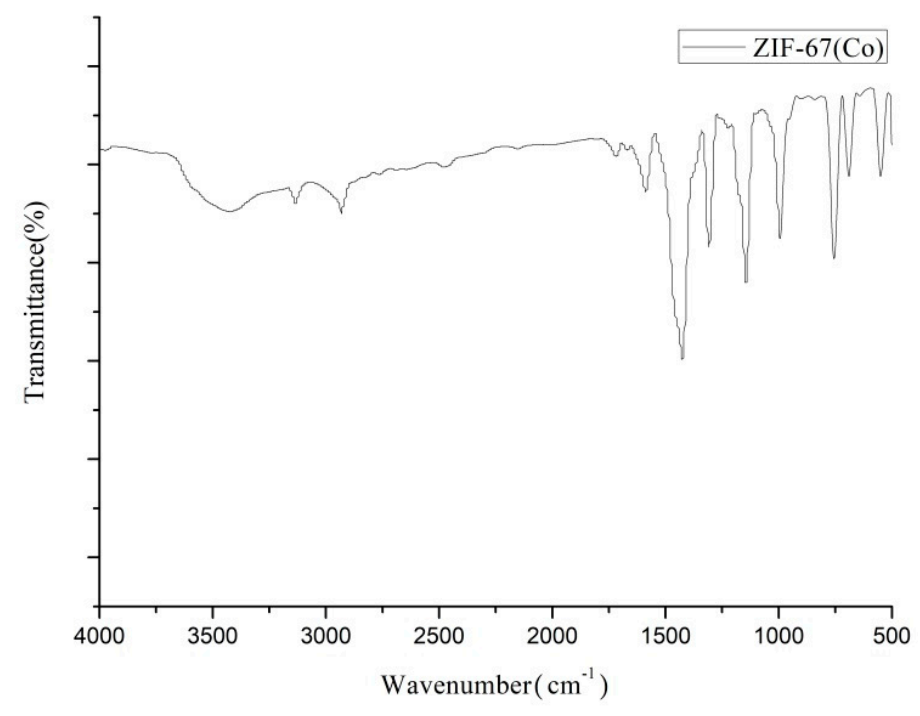

Figure 4. FT-IR spectra of ZIF-67(Co).

The synthesized ZIF-67(Co) submicroscopic crystals had high thermostability, which was proved by TGA and differential scanning calorimetry (DSC) as shown in Figure 5. The test increased temperature to $873 \mathrm{~K}$ from room temperature at $5 \mathrm{~K} / \mathrm{min}$. When calcined below $373 \mathrm{~K}$, the total weight loss of the sample was very small (about $8 \%$ ), relating to the removal of guest molecules such as water. Between 373 and $510 \mathrm{~K}$, the curve remained smooth overall, indicating that the skeleton of ZIF-67(Co) has good thermal stability below $510 \mathrm{~K}$. When the temperature was greater than $520 \mathrm{~K}$, the mass loss began at the stage of skeletal decomposition. This was attributed to the collapse of the ligands, which was caused by the decomposition of 2-methylimidazole. The weight-loss process was complete at $620 \mathrm{~K}$, and the residue was $\mathrm{Co}_{3} \mathrm{O}_{4}$. 


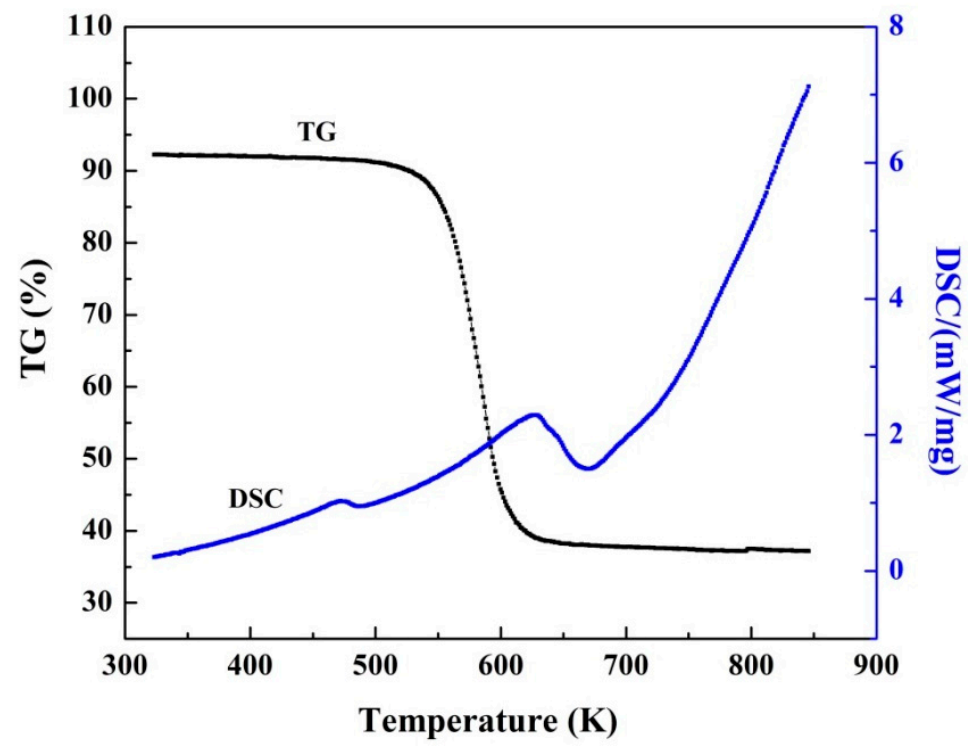

Figure 5. TGA and differential scanning calorimetry (DSC) curves of ZIF-67(Co) submicroscopic crystals.

\subsection{Catalytic Experiments}

\subsubsection{The Effect of Various Catalysts on the Reaction}

The comparison of the catalytic activities of different catalysts for the oxidation of limonene is summarized in Table 1. Using t-BHP as oxidant yielded carvone as the main product, and the reaction time was $8 \mathrm{~h}$. Besides, the synthetic method and XRD patterns about these MOFs have been revealed in supplementary material (Figures S1-S5)

Table 1. Comparison of the catalytic activities of various metal-organic frameworks (MOFs) for the oxidation of limonene.

\begin{tabular}{ccc}
\hline Catalysts & Conversion (\%) & Selectivity (\%) \\
\hline MIL-101(Fe) & 50.8 & 20.3 \\
ZIF-8(Zn) & 16.5 & 9.2 \\
ZIF-67(Co) & 35.7 & 32.6 \\
MIL-101(Cr) & 44.1 & 26.6 \\
HKUST-1(Cu) & 20.4 & 7.9 \\
MIL-125(Ti) & 18.2 & 10.1 \\
No catalyst & 26.7 & 0.05
\end{tabular}

Conditions: limonene: $2 \mathrm{~mL}$, catalyst: $100 \mathrm{mg}$, solvent: $15 \mathrm{~mL}$ acetic acid, oxidant: $15 \mathrm{~mL}$ t-BHP (tert-butyl hydroperoxide), temperature: $85^{\circ} \mathrm{C}$, reaction time: $8 \mathrm{~h}$.

First, the reactivity of several common catalysts was compared without any condition optimization. The activity of MIL-101(Fe)(Materials of Institute Lavoisier Frameworks) was the most outstanding for the oxidation of limonene-the conversion rate was 50.8\% after $8 \mathrm{~h}$; followed by MIL-101(Cr), whose conversion rate was $44.1 \%$. ZIF- 8 showed the worst activity, with a conversion rate of only $16.5 \%$. However, after the reaction, the filtrates from HKUST- $1(\mathrm{Cu})\left(\left[\mathrm{Cu}_{3}(\mathrm{BTC})_{2}\left(\mathrm{H}_{2} \mathrm{O}\right)_{3}\right]_{\mathrm{n}}\right), \mathrm{MIL}-101(\mathrm{Fe})$, and MIL-101(Cr) were light blue, dark red, and yellow-green, respectively. This indicates that metal ions, as metal centers, leaked during the reactions with HKUST-1(Cu), MIL-101(Fe), and MIL-101(Cr). On the other hand, ZIF-67 showed the highest selectivity, and the selectivity for carvone reached $36.6 \%$ after $8 \mathrm{~h}$ of reaction. The high selectivity of ZIF-67(Co) may be attributed to its unique ion centers. Heterogeneous catalysis with MOF materials is one of their extensively investigated applications [21]. 


\subsubsection{The Effect of the Catalyst Dosage on the Reaction}

The catalyst dosage had a significant effect on the oxidation of limonene. Five different dosages of ZIF-67(Co)-35, 60, 85, 110, and $135 \mathrm{mg}$-were used while keeping all the other reaction parameters fixed, and the experimental results are shown in Figure 6. Conversions of 4.75\%, 13.2\%, 28.1\%, 30.3\%, and $33.5 \%$, corresponding to the $35,60,85,110$, and $135 \mathrm{mg}$ catalyst loadings, respectively, were obtained in the experiment. With increasing ZIF-67(Co) dosage, the conversion of limonene increased. When the amount of catalyst was $135 \mathrm{mg}$, the conversion of limonene was 33.5\%. Interestingly, the selectivity for carvone increased at low catalyst contents and then decreased, relative to increasing content of the catalyst. When the dosage of the catalyst was $85 \mathrm{mg}$, the selectivity for carvone reached the maximum value (36.7\%). After that, the yield of carvone decreased slightly as the amount of catalyst continued to increase, but the rate of change was small.

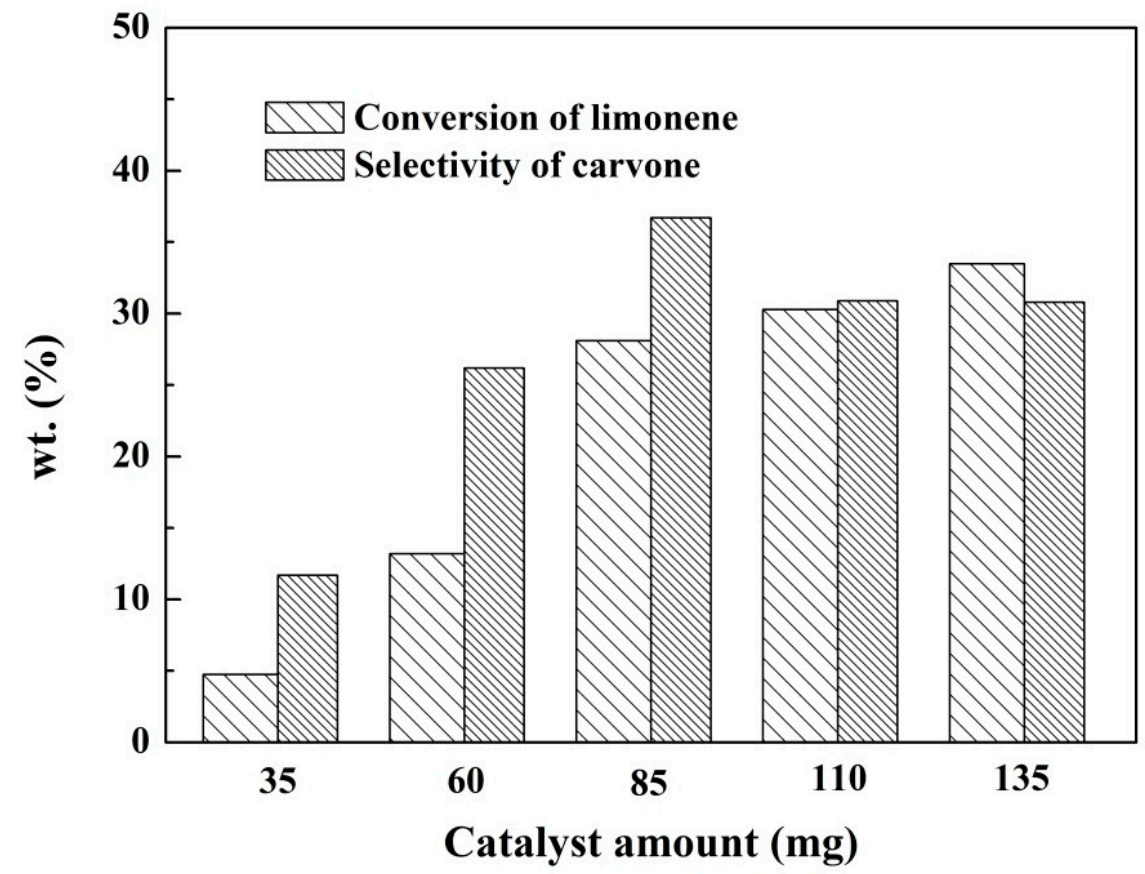

Figure 6. The effect of the catalyst dosage on the reaction. Conditions: limonene: $2 \mathrm{~mL}$, catalyst: ZIF-67(Co), solvent: $15 \mathrm{~mL}$ acetic acid, oxidant: $15 \mathrm{~mL}$ t-BHP, temperature: $85^{\circ} \mathrm{C}$, reaction time: $8 \mathrm{~h}$.

\subsubsection{The Effects of Various Oxidizing Agents on the Reaction}

Choosing a suitable oxidant is very important for improving the conversion and selectivity of catalytic oxidation, because oxidants are one of the key factors in catalytic oxidation. We tried to get air in the reaction to use oxygen as a reagent. In addition, hydrogen peroxide and $t$-BHP were used as oxidants. The results of these experiments are recorded in Table 2. When t-BHP (70\%) was added to the system, the conversion of limonene increased to $28.1 \%$, and the selectivity for carvone was $36.7 \%$. However, if hydrogen peroxide $(30 \%)$ was used as oxidant, the conversion of limonene and the selectivity decreased significantly.

Table 2. The effect of various oxidizing agents on the reaction.

\begin{tabular}{ccc}
\hline Oxidant & Conversion (\%) & Selectivity (\%) \\
\hline Air & 11.3 & 30.9 \\
$30 \% \mathrm{H}_{2} \mathrm{O}_{2}$ & 6.8 & 9.9 \\
$70 \% \mathrm{t}-\mathrm{BHP}$ & 28.1 & 36.7
\end{tabular}

Conditions: limonene: $2 \mathrm{~mL}$, catalyst: $85 \mathrm{mg}$ of ZIF-67(Co), solvent: $15 \mathrm{~mL}$ acetic acid, oxidant: $5 \mathrm{~mL} \mathrm{H}_{2} \mathrm{O}_{2}(30 \%)$ or $5 \mathrm{~mL}$ t-BHP, temperature: $85^{\circ} \mathrm{C}$, reaction time: $8 \mathrm{~h}$. 


\subsubsection{The Effect of the Dosage of the Oxidant on the Reaction}

Experimental results on the effect of oxidant dosage on the reaction were shown in Figure 7. We noticed that the conversion of limonene increased with increasing amounts of t-BHP. When the amount of t-BHP was $7 \mathrm{~mL}$, the conversion of limonene was $33.1 \%$. Meanwhile, the selectivity for carvone increased and then decreased with the increase in t-BHP. We also found that the selectivity for carvone reached its maximum (43.5\%) when the dosage of oxidant was $3 \mathrm{~mL}$. After that, increasing the amount of oxidant increased the degree of oxidation, resulting in a decrease of selectivity and yield.

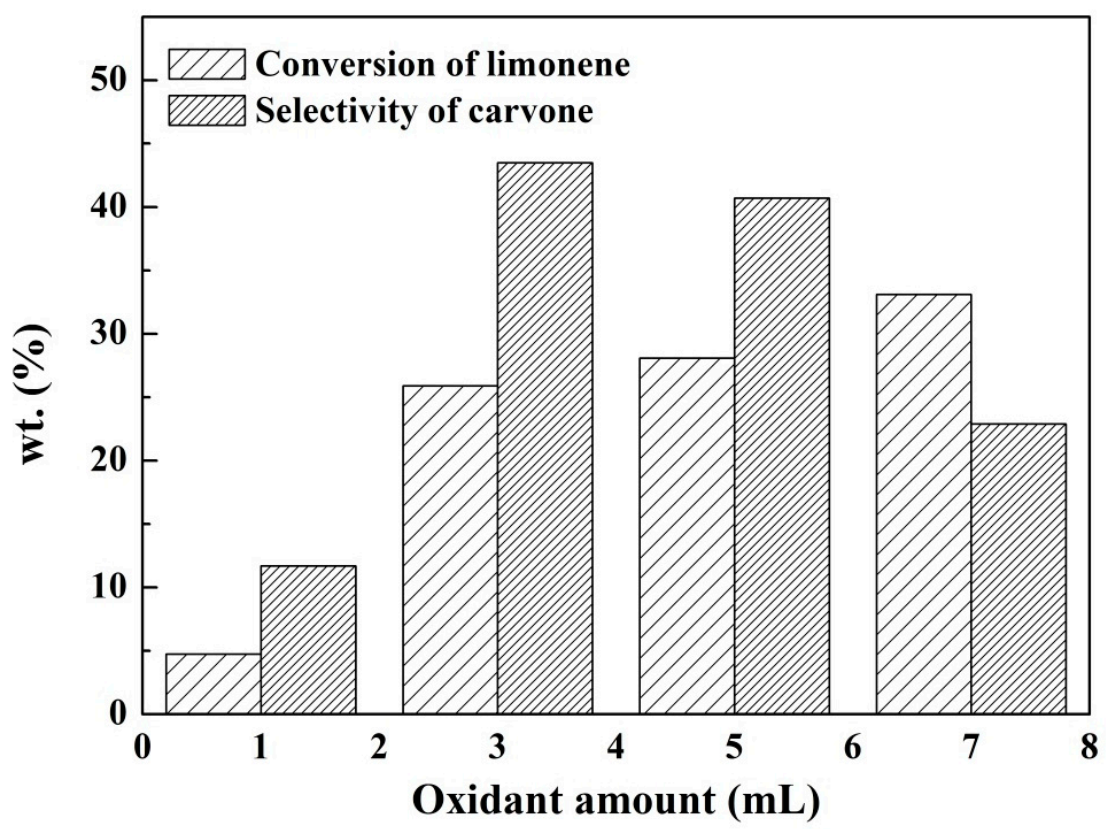

Figure 7. The effect of the oxidant dosage on the reaction. Conditions: limonene: $2 \mathrm{~mL}$, catalyst: ZIF-67(Co), solvent: $15 \mathrm{~mL}$ acetic acid, oxidant: t-BHP, temperature: $85^{\circ} \mathrm{C}$, reaction time: $8 \mathrm{~h}$.

\subsubsection{The Effects of Different Solvents on the Reaction}

The solvent is an important factor affecting heterogeneous catalytic reaction systems. The polarity, acidity, viscosity, and volatility of solvents have a great influence on the performance and reactivity of the catalyst. Some experiments were carried out to study the effects of different solvents on the catalytic oxidation of limonene by ZIF-67(Co), and the results are shown in Table 3. We found that limonene conversion and carvone selectivity were higher when benzene was used as solvent than with acetic acid, acetic anhydride, or ethyl acetate.

Table 3. The effect of different solvents on the reaction.

\begin{tabular}{ccc}
\hline Solvent & Conversion (\%) & Selectivity (\%) \\
\hline Acetic acid & 25.9 & 33.3 \\
Acetic & 38.1 & 15.9 \\
anhydride & 42.6 & 23.1 \\
Ethyl acetate & 20.3 & 49.4 \\
Benzene &
\end{tabular}

Conditions: limonene: $2 \mathrm{~mL}$, catalyst: $85 \mathrm{mg}$ of ZIF-67(Co), solvent: $15 \mathrm{~mL}$, oxidant: $3 \mathrm{~mL} \mathrm{t}-\mathrm{BHP}$, temperature: $85^{\circ} \mathrm{C}$, reaction time: $8 \mathrm{~h}$.

\subsubsection{The Effect of the Temperature on the Reaction}

The oxidation of limonene was examined over the temperature range of $55-95^{\circ} \mathrm{C}$, and the results are shown in Figure 8. The conversion of limonene increased quickly from $6.5 \%$ to $30.5 \%$ for a reaction 
time of $8 \mathrm{~h}$, when the temperature was increased from 55 to $65^{\circ} \mathrm{C}$. Thereafter, the trend of conversion had a slow decline. Interestingly enough, the selectivity for carvone reached its maximum $(48.7 \%)$ at $85{ }^{\circ} \mathrm{C}$. This might be because the activity of the catalyst definitely increased at the beginning of the temperature rise, so the conversion of limonene increased rapidly. However, after the temperature reached a certain value, the catalytic activity of the material did not increase and the byproduct formation did increase, so the selectivity for carvone decreased.

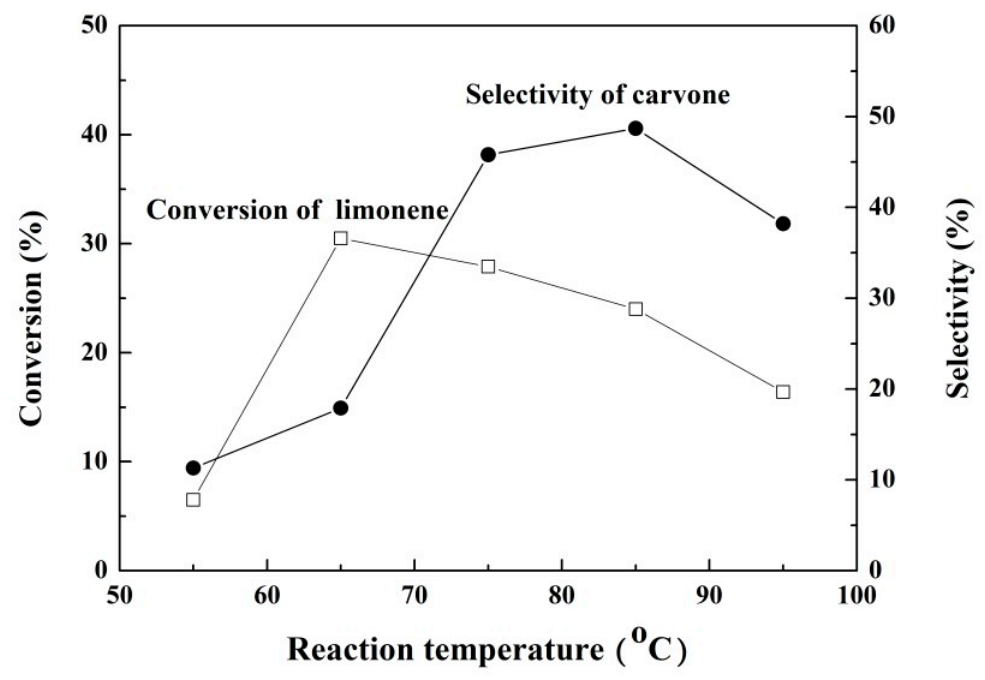

Figure 8. The effect of temperature on the reaction. Conditions: limonene: $2 \mathrm{~mL}$, catalyst: $85 \mathrm{mg}$ ZIF-67(Co), solvent: $12 \mathrm{~mL}$ benzene, oxidant: $3 \mathrm{~mL}$ t-BHP, reaction time: $8 \mathrm{~h}$.

\subsubsection{The Effect of the Reaction Time on the Reaction}

The catalytic oxidation of limonene, using the above conditions for different reaction times, was studied. As can be seen in Figure 9, the conversion of limonene increased with increasing reaction time, and the conversion was $37.8 \%$ at $12 \mathrm{~h}$. Meanwhile, the selectivity for carvone increased first, reached a maximum at $6 \mathrm{~h}(57.7 \%)$, and then decreased. Owing to the fact that t-BHP is not completely decomposed over short times, the oxidation efficiency was undesirable, and with increasing reaction time, there were corresponding increases in the oxidants' oxidation capacity as well as the conversion rate. However, selectivity of carvone decreased with reaction time increased because of the depth oxidation of carvone and by-product increased.

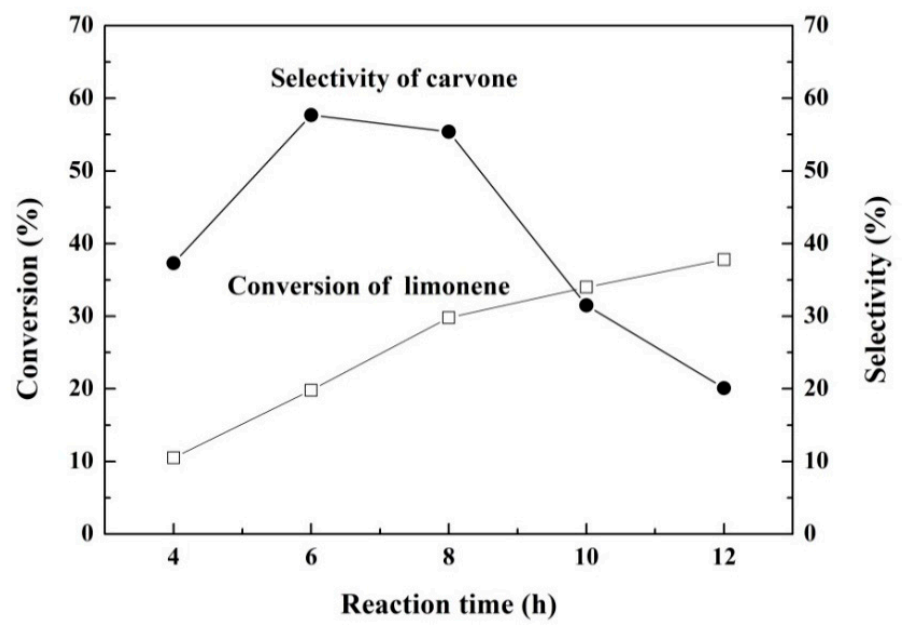

Figure 9. The effect of the reaction time on the reaction. Conditions: limonene: $2 \mathrm{~mL}$, catalyst: $85 \mathrm{mg}$ ZIF-67(Co), solvent: $12 \mathrm{~mL}$ benzene, oxidant: $3 \mathrm{~mL} \mathrm{t-BHP,} \mathrm{temperature:} 75{ }^{\circ} \mathrm{C}$. 


\subsubsection{Study of the Catalyst Stability}

Stability is an important parameter of catalyst performance. In order to investigate the stability of ZIF-67(Co), XRD spectra of ZIF-67(Co) before and after the first reaction round were obtained and are presented here. As shown in Figure 10, the characteristic peak was still present, but its strength decreased slightly. So, we can be sure that the structure of ZIF-67 still existed.

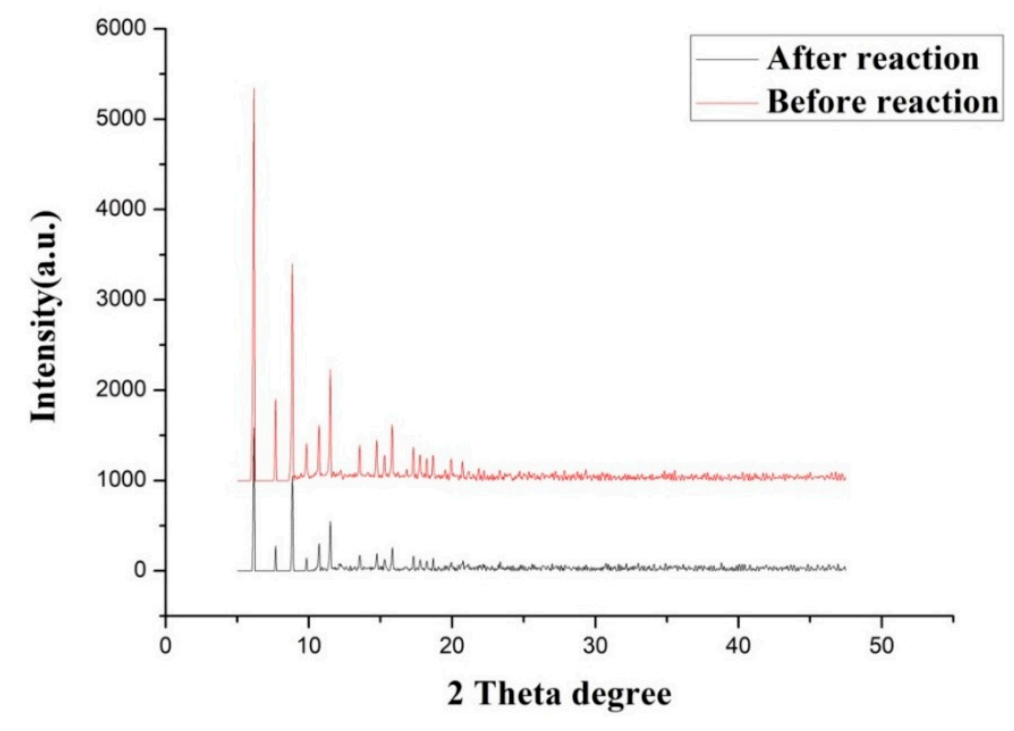

Figure 10. XRD spectra of ZIF-67(Co) as synthesized and after the first recycle.

Concurrently, the specific data about repetitive experiments are revealed in Table 4.

Table 4. The data from reuse experiments.

\begin{tabular}{cccc}
\hline Times & Conversion (\%) & Selectivity (\%) & TON \\
\hline First round & 29.8 & 55.4 & 18.1 \\
Second round & 33.5 & 41.6 & 13 \\
Third round & 32.5 & 28.0 & 8.7 \\
\hline
\end{tabular}

Conditions: limonene: $2 \mathrm{~mL}$, catalyst: $85 \mathrm{mg}$ of ZIF-67(Co), solvent: $12 \mathrm{~mL}$ benzene, oxidant: $3 \mathrm{~mL}$ t-BHP, temperature: $75^{\circ} \mathrm{C}$, reaction time: $8 \mathrm{~h}$. Turnover number $(\mathrm{TON})=$ carvone (yield) $\mathrm{mmol} /$ total Co site mmol.

The data in Table 4 reveal the repeatability of ZIF-67(Co) in the catalytic oxidation of limonene. As can be seen from the data in Table 4, we found that the selectivity for carvone declined slightly in the second round. At the same time, the conversion of limonene declined as well. We conclude that this may be related to a partial collapse of the basic structure of ZIF-67(Co).

\section{Materials and Methods}

\subsection{Materials and Solvents}

Cobaltous nitrate hexahydrate was supplied by Xilong Chemical Co., Ltd. (Shantou, China) and 2-methylimidazole was obtained from Sinopharm Chemical Reagent Co., Ltd. (Shanghai, China). All other reactants used in the synthesis of the ZIF-67(Co) catalyst samples were supplied by Xilong Chemical Co., Ltd. Methanol and acetic acid were purchased from Xilong Chemical Co., Ltd. The tert-butyl hydroperoxide and limonene were obtained from Adamas Reagent Co., Ltd. (Shanghai, China). 


\subsection{Catalyst Preparation}

In a typical preparation process [33], $0.45 \mathrm{~g}$ cobaltous nitrate hexahydrate was dissolved in $3 \mathrm{~mL}$ of distilled water, and then $5.5 \mathrm{~g}$ of 2-methylimidazole was dissolved in $100 \mathrm{~mL}$ of distilled water. Then the two solutions were mixed evenly and stirred at room temperature for $6 \mathrm{~h}$. The products obtained were washed with distilled water and methanol, and then dried in at $80^{\circ} \mathrm{C}$ for $24 \mathrm{~h}$.

\subsection{Catalyst Characterization}

ZIF-67(Co) was characterized through a series of techniques. The diffraction patterns of the materials and the residual catalyst were obtained by powder X-ray diffraction (XRD, Rigaku Co., Tokyo, Japan) experiments using $\mathrm{Cu} \mathrm{K} \alpha$ band radiation on a D/max-3B spectrometer. Scans were made over the $2 \theta$ range of $10-90^{\circ}$ with a scan rate of $10^{\circ} / \mathrm{min}$ (wide-angle diffraction). Pore size distributions, pore volumes, and specific surface area were measured by nitrogen adsorption/desorption using a Micromeritics ASAP 2460(Micromeritics, Norcross, GA, USA) at $77 \mathrm{~K}$. The specific surface areas were calculated by the Brunauer-Emmett-Teller $\left(\mathrm{S}_{\mathrm{BET}}\right)$ and Langmuir methods, and the pore volumes and pore sizes were calculated by the $\mathrm{BJH}$ (Barrett-Joyner-Halenda) method. Thermogravimetric analysis (TGA) curves and differential scanning calorimetry (DSC) determinations were carried out on a NETZSCH STA 449 F3 synchronous TG-DSC thermal analyzer (Nuremberg, Germany) with a scanning rate of $5 \mathrm{~K} / \mathrm{min}$ in a dry nitrogen atmosphere and heating from room temperature to $1073 \mathrm{~K}$. The FT-IR(Fourier transform infrared spectroscopy) measurements were performed on a Thermo Nicolet 8700 instrument(Wilmington, MA, USA). Potassium bromide pellets were used in FT-IR experiments at a spectral resolution of $4 \mathrm{~cm}^{-1}$. Scanning electron microscopy (SEM) images were taken on a Quanta 200FEG microscope (FEI, Hillsboro, OR, USA) at an accelerating voltage of $15 \mathrm{kV}$ with the pressure in the sample chamber set to $2.7 \times 10^{-5} \mathrm{~Pa}$. Double-sided adhesive tape was bonded on the carrier disc, then a small amount of powder sample was placed near the center of the carrier disc on the adhesive tape. Then, a rubber ball was used to blow the sample outward along the radial direction of the load plate, so that the powder was evenly distributed on the tape. The tape was then coated with conductive silver paste to connect the sample to the carrier plate. After the silver paste was dried, the final gold steaming process could be carried out.

\subsection{Catalytic Performance}

In a typical reaction, $2 \mathrm{~mL}$ limonene with varying amounts of catalyst and solvents were used as received, without further purification, in a $25 \mathrm{~mL}$ three-neck flask. Each set of experiments was performed at a corresponding temperature, under atmospheric pressure and magnetic stirring, using an appropriate amount of solvent, e.g., acetic acid, acetic anhydride, ethyl acetate, benzene, etc. Afterwards, the catalyst was separated by filtration, and the sample solution was dried with anhydrous magnesium sulfate. A final filtration was carried out, and the samples were qualitatively and quantitatively analyzed by gas chromatography (GC-9560, HUAAI Chromatography, Shanghai, China), with a capillary column AE.OV-624, $30 \mathrm{~m}$ in length, $0.25 \mathrm{~mm}$ i.d., $0.5 \mu \mathrm{m}$ film thickness, and an FID (Flame ionization detector).

In order to assess the stability of the ZIF-67(Co), some sets of a repeatability experiment were performed. After the first reaction, the catalyst was centrifuged and separated from the reaction system, and after repeated washing with distilled water and anhydrous ethanol, the catalyst was reactivated at $90^{\circ} \mathrm{C}$ in the vacuum drying chamber for $12 \mathrm{~h}$. Thereafter, the reactor was supplied with the recovered dry catalyst, new reagents, and solvent for the second reaction. We repeated the above process three times.

\section{Conclusions}

In conclusion, we proved that the zeolitic imidazolate framework ZIF-67(Co) was an efficient catalyst for the liquid-phase catalytic oxidation of limonene, under relatively mild reaction conditions, 
to carvone. Based on current research, the catalytic oxidation of limonene comprises two parallel reactions, namely a synergistic reaction and a free-radical reaction. Carvone is the product of the free-radical reaction of limonene at the allyl group. The synergistic reaction produced limonene-1,2-oxides and limonene-1,2-diols. Meanwhile, under acidic conditions, the 1,2-oxide of limonene could be hydrolyzed to produce the 1,2-diol of limonene, and the 1,2-diol of limonene could be further rearranged and converted to carvone.

This is the first report on catalyzing the oxidation of limonene using ZIF-67(Co) as catalyst. It was revealed that ZIF-67(Co) was an efficient catalyst, with selectivity of $55.4 \%$ for carvone in the catalytic oxidation of limonene, and could be reused with similar activity.

Supplementary Materials: The following are available online at http://www.mdpi.com/2073-4344/9/4/374/s1, Figure S1: XRD pattern of MIL-101(Cr), Figure S2: XRD pattern of MIL-125(Ti), Figure S3: XRD pattern of HKUST-1(Cu), Figure S4: XRD pattern of ZIF-8(Zn), Figure S5: XRD pattern of MIL-101(Fe).

Author Contributions: Conceptualization, J.W. and Y.L.; Data curation, Z.Y. and Y.L.; Formal analysis, Y.L. and W.W.; Investigation, Y.L., Y.Y., D.C., and Z.L.; Methodology, J.W.; Project administration, J.W. and Z.Y.; Software, Z.L., Y.A., and L.Z.; Supervision, J.W. and Z.Y.; Writing-original draft, Y.L.; Writing—review and editing, J.W. and Z.Y.

Funding: This research was funded by National Natural Science Foundation of China (Project 21573193 and 21464016). The authors also thank the Key Projects for Research and Development of Yunnan Province (2018BA065), the Scientific Research Fund of Department of Yunnan Education (Project 2016CYH04 and 2017ZZX223) for financial support.

Acknowledgments: The work was supported by National Natural Science Foundation of China (Project 21573193 and 21464016). The authors also thank the Key Projects for Research and Development of Yunnan Province (2018BA065), the Scientific Research Fund of Department of Yunnan Education (Project 2016CYH04 and 2017ZZX223), and the Program for Innovation Team of Yunnan Province and Key Laboratory of Advanced Materials for Wastewater Treatment of Kunming for financial support.

Conflicts of Interest: The authors declare no conflict of interest.

\section{References}

1. Murphy, E.F.; Mallat, T.; Baiker, A. Allylic oxofunctionalization of cyclic olefins with homogeneous and heterogeneous catalysts. Catal. Today 2000, 31, 115-126. [CrossRef]

2. Sakthivel, A.; Dapurkar, S.E.; Selvam, P. Allylic oxidation of cyclohexene over chromium containing mesoporous molecular sieves. Appl. Catal. A-Gen. 2003, 246, 283-293. [CrossRef]

3. Goncalves, J.C.; Oliveira, F.S.; Benedito, R.B.; Sousa, D.P.; de Almeida, R.N.; de Araújo, D.A. Antinociceptive Activity of (-)-Carvone: Evidence of Association with Decreased Peripheral Nerve Excitability. Biol. Pharm. Bull. 2008, 31, 1017-1020. [CrossRef] [PubMed]

4. de Carvalho, C.C.C.R.; da Fonseca, M.M.R. Carvone: Why and how should one bother to produce this terpene. Food Chem. 2006, 95, 413-422.

5. Li, N.; Wang, F.; Li, M. The Chemical Modification of L(-)-Carvone and its Biological Activity to Three Fungal Pathogens of Plant. J. Mt. Agric. Biol. 2010. [CrossRef]

6. Linder, S.M.; Greenspan, F.P. Reactions of Limonene Monoxide. The Synthesis of Carvone. J. Org. Chem. 1957, 22, 949-951. [CrossRef]

7. Robles-Dutenhefner, P.A.; Brandão, B.B.N.S.; de Sousa, L.F.; Gusevskaya, E.V. Solvent-free chromium catalyzed aerobic oxidation of biomass-based alkenes as a route to valuable fragrance compounds. Appl. Catal. A Gen. 2011, 399, 172-178. [CrossRef]

8. Caovilla, M.; Caovilla, A.; Pergher, S.B.C.; Esmelindro, M.C.; Fernandes, C.; Dariva, C.; Bernardo-Gusmão, K.; Oestreicher, E.G.; Antunes, O.A.C. Catalytic oxidation of limonene, $\alpha$-pinene and $\beta$-pinene by the complex $\left[\mathrm{Fe}^{\mathrm{III}}(\mathrm{BPMP}) \mathrm{Cl}(\mu-\mathrm{O}) \mathrm{Fe}^{\mathrm{III}} \mathrm{Cl}_{3}\right]$ biomimetic to MMO enzyme. Catal. Today 2008, 133, 695-698.

9. Młodzik, J.; Wróblewska, A.; Makuch, E.; Wróbel, R.J.; Michalkiewicz, B. Fe/EuroPh catalysts for limonene oxidation to 1,2-epoxylimonene, its diol, carveol, carvone and perillyl alcohol. Catal. Today 2015, 268, 111-120. [CrossRef]

10. Wróblewska, A.; Makuch, E.; Miądlicki, P. The oxidation of limonene at raised pressure and over the various titanium-silicate catalysts. Pol. J. Chem. Technol. 2015, 17, 82-87. [CrossRef] 
11. Li, J.; Li, Z.; Zi, G.; Yao, Z.; Luo, Z.; Wang, Y.; Xue, D.; Wang, B.; Wang, J. Synthesis, characterizations and catalytic allylic oxidation of limonene to carvone of cobalt doped mesoporous silica templated by reed leaves. Catal. Commun. 2015, 59, 233-237. [CrossRef]

12. Drake, T.; Ji, P.; Lin, W. Site Isolation in Metal-Organic Frameworks Enables Novel Transition Metal Catalysis. Acc. Chem. Res. 2018, 51, 2129-2138. [CrossRef]

13. Dhakshinamoorthy, A.; Li, Z.; Garcia, H. Catalysis and photocatalysis by metal organic frameworks. Chem. Soc. Rev. 2018, 47, 8134-8172. [CrossRef]

14. Mukherjee, S.; Desai, A.V.; Ghosh, S.K. Potential of metal-organic frameworks for adsorptive separation of industrially and environmentally relevant liquid mixtures. Coord. Chem. Rev. 2018, 367, 82-126. [CrossRef]

15. Li, H.; Wang, K.; Sun, Y.; Lollar, C.T.; Li, J.; Zhou, H.-C. Recent advances in gas storage and separation using metal-organic frameworks. Mater. Today 2018, 21, 108-121. [CrossRef]

16. Li, J.; Wang, X.; Zhao, G.; Chen, C.; Chai, Z.; Alsaedi, A.; Hayat, T.; Wang, X. Metal-organic framework-based materials: superior adsorbents for the capture of toxic and radioactive metal ions. Chem. Soc. Rev. 2018, 47, 2322-2356. [CrossRef] [PubMed]

17. Lima, I.F.; Corraza, M.L.; Cardozo-Filho, L.; Márquez-Alvarez, H.; Antuntes, O.A.C. Oxidation of limonene catalyzed by Metal(Salen) complexes. Braz. J. Chem. Eng. 2006, 23. [CrossRef]

18. Raj, N.K.K.; Puranik, V.G.; Gopinathan, C.; Ramaswarmy, A.V. Selective oxidation of limonene over sodium salt of cobalt containing sandwich-type polyoxotungstate $\left[\mathrm{WCo}_{3}\left(\mathrm{H}_{2} \mathrm{O}\right)_{2}\left\{\mathrm{~W}_{9} \mathrm{CoO}_{34}\right\}_{2}\right]^{10-}$. Appl. Catal. A-Gen. 2003, 256, 265-273.

19. Jiang, D.; Mallat, T.; Meier, D.M.; Urakawa, A.; Baiker, A. Copper metal-organic framework: Structure and activity in the allylic oxidation of cyclohexene with molecular oxygen. J. Catal. 2010, 270, 26-33. [CrossRef]

20. Yang, H.; He, X.-W.; Wang, F.; Kang, Y.; Zhang, J. Doping copper into ZIF-67 for enhancing gas uptake capacity and visible-light-driven photocatalytic degradation of organic dye. J. Mater Chem. 2012, 22, 21849-21851. [CrossRef]

21. Kuruppathparambil, R.R.; Jose, T.; Babu, R.; Hwang, G.-Y.; Kathalikkattil, A.M.; Kim, D.-W.; Park, D.-W. A room temperature synthesizable and environmental friendly heterogeneous ZIF-67 catalyst for the solvent less and co-catalyst free synthesis of cyclic carbonates. Appl. Catal. B-Environ. 2016, 182, 562-569. [CrossRef]

22. Yang, L.; Yu, L.; Sun, M.; Gao, C. Zeolitic imidazole framework-67 as an efficient heterogeneous catalyst for the synthesis of ethyl methyl carbonate. Catal. Commun. 2014, 54, 86-90. [CrossRef]

23. Zhu, M.; Srinivas, D.; Bhogeswararao, S.; Ratnasamy, P.; Carreon, M.A. Catalytic activity of ZIF-8 in the synthesis of styrene carbonate from $\mathrm{CO}_{2}$ and styrene oxide. Catal. Commun. 2013, 32, 36-40. [CrossRef]

24. Yang, L.; Yu, L.; Diao, G.; Sun, M.; Cheng, G.; Chen, S. Zeolitic imidazolate framework-68 as an efficient heterogeneous catalyst for chemical fixation of carbon dioxide. J. Mol. Catal. A-Chem. 2014, 392, 278-283. [CrossRef]

25. Jose, T.; Hwang, Y.; Kim, D.-W.; Kim, M.-I.; Park, D.-W. Functionalized zeolitic imidazolate framework F-ZIF-90 as efficient catalyst for the cycloaddition of carbon dioxide to allyl glycidyl ether. Catal. Today 2015, 245, 61-67. [CrossRef]

26. Banerjee, R.; Phan, A.; Wang, B.; Knobler, C.; Furukawa, H.; O’Keeffe, M.; Yaghi, O.M. High-throughput synthesis of zeolitic imidazolate frameworks and application to $\mathrm{CO}_{2}$ capture. Science 2008, 319, 939-943. [CrossRef] [PubMed]

27. Li, K.H.; Olson, D.H.; Seidel, J.; Emge, T.J.; Gong, H.W.; Zeng, H.P.; Li, J. Zeolitic imidazolate frameworks for kinetic separation of propane and propene. J. Am. Chem. Soc. 2009, 131, 10368-10369. [CrossRef] [PubMed]

28. Yang, J.; Zhang, F.; Lu, H.; Hong, X.; Jiang, H.; Wu, Y.; Li, Y. Hollow Zn/Co ZIF Particles Derived from Core-Shell ZIF-67@ZIF-8 as Selective Catalyst for the Semi-Hydrogenation of Acetylene. Angew. Chem. Int. Ed. Engl. 2015, 127, 11039-11043. [CrossRef]

29. Kuo, C.-H.; Tang, Y.; Chou, L.-Y.; Sneed, B.T.; Brodsky, C.N.; Zhao, Z.; Tsung, C.K. Yolk-shell nanocrystal@ZIF-8 nanostructures for gas-phase heterogeneous catalysis with selectivity control. J. Am. Chem. Soc. 2012, 134, 14345-14348. [CrossRef]

30. Wee, L.H.; Lescouet, T.; Ethiraj, J.; Bonino, F.; Vidruk, R.; Garrier, E.; Packet, D.; Bordiga, S.; Farrusseng, D.; Herskowitz, M.; et al. Hierarchical zeolitic imidazolate framework-8 catalyst for monoglyceride synthesis. ChemCatChem 2013, 5, 3562-3566. [CrossRef]

31. Chizallet, C.; Lazare, S.; Bazer-Bachi, D.; Bonnier, F.; Lecocq, V.; Soyer, E.; Quoineaud, A.-A.; Bats, N. Catalysis of transesterification by a nonfunctionalized metal- organic framework: acido-basicity at the external surface 
of ZIF-8 probed by FTIR and ab initio calculations. J. Am. Chem. Soc. 2010, 132, 12365-12377. [CrossRef] [PubMed]

32. Shi, Q.; Chen, Z.; Song, Z.; Li, J.; Dong, J. Synthesis of ZIF-8 and ZIF-67 by Steam-Assisted Conversion and an Investigation of Their Tribological Behaviors. Angew. Chem. Int. Ed. Engl. 2011, 50, 672-675. [CrossRef] [PubMed]

33. Qian, J.; Sun, F.; Qin, L.; Li, J.; Dong, J. Hydrothermal synthesis of zeolitic imidazolate framework-67 (ZIF-67) nanocrystals. Mater. Lett. 2012, 82, 220-223. [CrossRef]

(C) 2019 by the authors. Licensee MDPI, Basel, Switzerland. This article is an open access article distributed under the terms and conditions of the Creative Commons Attribution (CC BY) license (http://creativecommons.org/licenses/by/4.0/). 